\title{
Potential factors associated with clinical stage of nasopharyngeal carcinoma at diagnosis: a case-control study
}

\author{
Jun-Ting Ren ${ }^{1 \dagger}$, Meng-Yu Li ${ }^{1 \dagger}$, Xiao-Wen Wang ${ }^{1}$, Wen-Qiong Xue ${ }^{2}$, Ze-Fang Ren ${ }^{{ }^{*}}$ and Wei-Hua Jia ${ }^{1,2^{*}}$
}

\begin{abstract}
Background: In China, most patients with nasopharyngeal carcinoma (NPC) are diagnosed at a late stage and consequently have a poor prognosis. This study aimed to investigate potential factors associated with the clinical stage of NPC at diagnosis.

Methods: Data were obtained from 118 patients with early-stage NPC and 274 with late-stage NPC who were treated at Sun Yat-sen University Cancer Center between August 2014 and July 2015. Patients were individually matched by age, sex, and residence, and a conditional logistic regression model was applied to assess the associations of clinical stage at diagnosis with socioeconomic status indicators, knowledge of NPC, physical examinations, patient interval, and risk factors for NPC.

Results: Although knowledge of early NPC symptoms, smoking cessation, and patient interval were important factors, the number of cigarettes smoked per day, motorbike ownership, and physical examination exhibited the strongest associations with the clinical stage of NPC at diagnosis. Compared with smoking fewer than ten cigarettes a day, smoking 10-30 cigarettes [odds ratio (OR) 4.03; 95\% confidence interval (Cl) 1.11-14.68] or more than 30 cigarettes (OR 11.46; 95\% Cl 1.26-103.91) was associated with an increased risk of late diagnosis. Compared with not owning a motorbike, owning a motorbike (OR $0.38 ; 95 \% \mathrm{Cl} 0.23-0.64$ ) was associated with early diagnosis. Subjects who underwent physical examinations were less likely to receive a late diagnosis than those who did not undergo examinations (OR 0.50; 95\% Cl 0.28-0.89). However, indicators of wealth were not significant factors.
\end{abstract}

Conclusions: Initiatives to improve NPC patient prognosis should aim to promote knowledge about early symptoms and detection, health awareness, and accessibility to health facilities among all patients, regardless of socioeconomic status.

Keywords: Nasopharyngeal carcinoma, Stage, Socioeconomic status, Cancer cognition, China

\section{Background}

Globally, nasopharyngeal carcinoma (NPC) is a relatively uncommon disease, with estimates of 86,700 new cases and 50,800 deaths worldwide in 2012 [1]. However, NPC is the sixth most common cancer affecting men in

\footnotetext{
*Correspondence: renzef@mail.sysu.edu.cn; jiawh@sysucc.org.cn ${ }^{\dagger} J u n-T i n g$ Ren and Meng-Yu Li contributed equally to this work 1 School of Public Health, Sun Yat-sen University, 74 Zhongshan 2nd Rd, Guangzhou 510080, Guangdong, P. R. China

${ }^{2}$ State Key Laboratory of Oncology in South China, Collaborative Innovation Center for Cancer Medicine, Sun Yat-sen University Cancer Center, 651 Dongfeng East Rd, Guangzhou 510060, Guangdong, P. R. China
}

South China [1], with incidences as high as $20-30$ per 100,000 individuals [2]. Most patients in this region are initially diagnosed with late-stage disease $[3,4]$. Among patients with NPC, survival is largely dependent on the clinical stage at diagnosis [5]: the 5-year overall survival rates exceed $90 \%$ for early-stage (stage I and II) patients $[6,7]$, but are less than $50 \%$ for late-stage (stage III and IV) patients [8]. Therefore, early diagnosis is essential to improving the prognosis of NPC.

To date, only three studies have investigated the association between the patient interval, defined in accordance with the Aarhus Statement as the time interval between 
the date of the first symptom and the date of the first presentation (i.e., first medical consultation) which contains "appraisal interval" (time taken to interpret bodily changes/symptoms) and "help-seeking interval" (time taken to act upon those interpretations and seek help) [9], and the diagnosis of late-stage NPC [10-12]. However, these studies neglected to address the interactions among multiple potential factors related to the clinical stage at diagnosis and did not provide information that would facilitate the implementation of measures to improve early NPC diagnostic rates. Therefore, a more comprehensive study of the factors that might affect the clinical stage of NPC at diagnosis is needed.

Existing studies of various cancers have demonstrated a relationship between socioeconomic status (SES) and clinical stage of NPC at diagnosis [13-16]. SES can serve as an indicator of various underlying health-related factors, and individuals with a higher SES may be diagnosed at an earlier stage than those with a lower SES [17-19]. In addition to SES, symptom knowledge [20], physical examinations [21, 22], and patient interval [23] were found to independently associate with the stage of NPC at diagnosis, and factors such as salted fish consumption, cigarette smoking, and a family cancer history are known risk factors for NPC [24, 25]. The knowledge and biological effects of these risk factors might be associated with the clinical stage of NPC at diagnosis and confound the effects of other factors.

Therefore, in the present study, we investigated the associations of the clinical stage of NPC at diagnosis with a series of SES indicators, knowledge of both NPC symptoms and risk factors, physical examinations, patient interval, smoking history, salted fish consumption, and family cancer history among patients at the Sun Yat-sen University Cancer Center (Guangzhou, China), with the aim of developing measures to improve early diagnosis and prognosis of NPC.

\section{Patients and methods \\ Patient selection}

We reviewed the clinical records of all NPC patients who were treated between August 1, 2014 and July 31, 2015 at Sun Yat-sen University Cancer Center, the largest cancer hospital in South China. Patients who were diagnosed between 2012 and 2015 and had histologically confirmed NPC were included. Patients with tumors at secondary sites were excluded from this study.

All patients with early-stage (I and II) NPC were selected and interviewed through telephone calls. Subsequently, each patient with early-stage disease was randomly matched with two or three patients with latestage (III and IV) disease according to residence (urban or rural), age ( \pm 5 years), and sex using a random number generation method.

\section{Data collection}

Patients' characteristics, including sex and tumor stage at diagnosis, were obtained from the hospital electronic record system. Tumor staging was based on the clinical TNM classification in accordance with the 2009 American Joint Committee on Cancer/Union for International Cancer Control (AJCC/UICC) staging system. After providing verbal consent, participants were interviewed via telephone by trained interviewers who used a structured questionnaire that solicited information about SES and other indicators.

SES indicators such as the highest degree of education, occupation, working hours per week, health insurance, residence ownership, residence structure, residence size $\left(\mathrm{m}^{2}\right)$, number of family members living in the residence, and ownership of household appliances were recorded. Occupation was categorized as (i) unskilled workers, including factory laborers, farmers, and other occupations requiring a low degree of education; (ii) skilled workers, including "white-collar" workers, technicians, and other workers with a high degree of education; or (iii) retired or unemployed. Residence ownership was classified as owning or not owning the residence; the latter included rented housing and government- or school-supported housing. Residence structures were categorized into bungalows, houses, apartments, and other types (e.g., dormitory or retail store). Income was shown to be unreliable as a single indicator [26], and was not included in the questionnaire.

We also collected information regarding the participants' knowledge of early NPC symptoms and risk factors. Early symptoms of NPC include epistaxis, tinnitus and deafness, nasal obstruction, headache, diplopia, and neck masses, whereas risk factors include Epstein-Barr virus (EBV) infection, genetic factors, living environment, and lifestyle [24]. If subjects answered positively to at least one point, they were classified as having knowledge about early symptoms or risk factors of NPC.

We investigated how patients were exposed to the known risk factor for NPC, such as family history of cancer, history of smoking, cigarette consumption, and salted fish consumption [24]. The family history of cancer was classified as no family cancer history, a family history of cancers excluding NPC, or a family cancer history of NPC. The smoking history was categorized as never smoker, former smoker, and current smoker. Cigarette consumption was categorized as fewer than ten cigarettes, 10-30 cigarettes, or more than 30 cigarettes per day. Salted fish consumption was categorized as seldom or never, monthly, or weekly. 
Subjects were further divided into two groups by the mean of patient interval (3 months).

\section{Composite wealth score calculation}

To establish a formula for accurate calculation of composite wealth score, we implemented a multiple correspondence analysis (MCA) on the structure, ownership, and area of residence, the ownership of personal car, motorbike, television, computer, air conditioner, vacuum cleaner, and washing machine, and occupation [26]. The MCA was extended with the intent to summarize the associations among a set of categorical variables in a small number of dimensions. In this process, the variables were transformed into new dimensions and given distinct values in each dimension [27]. Variables with more similar values in each dimension are more strongly associated with each other. The first dimension explains as much of the information from the data as possible, whereas each succeeding dimension explains as much of the remaining information as possible. Generally, only the first and second principal dimension scores are used to generate two-dimensional plots, and variables plotted near each other are positively interrelated [28].

A wealth score was computed by evaluating each variable by the weight reported in the first dimension and summing these weights. For example, the first-dimension weights for owning or not owning a car were -1.372 and 1.088 , and those for owning or not owning a vacuum cleaner were -1.415 and 0.609 . If a subject possessed a car but did not own a vacuum cleaner, the corresponding weights $(-1.372$ and 0.609$)$ were summed. This process was continued until the weights of all MCA variables were encompassed by this calculation. The composite wealth scores were then computed and used to divide the subjects into tertiles.

\section{Statistical analysis}

We compared the distributions of variables of interest between patients with early-stage and late-stage diseases, using the Chi square test for categorical variables and the Wilcoxon rank-sum test for continuous variables.

In accordance with the matched case-control design of the study, unadjusted and adjusted odds ratios (ORs) and corresponding 95\% confidence intervals (CIs) for all study factors were calculated using conditional logistic regression models adjusted for the education level, composite wealth score, and NPC risk factors such as smoking history, salted fish consumption frequency, and family cancer history. When one of these possible confounders was the variable of interest, the other possible confounders were adjusted. All statistical tests were twotailed, and a $P$ value $<0.05$ was considered significant.
Statistical analyses were performed using the R Studio software, version 0.99 .893 (https://www.rstudio.com/).

\section{Results}

Characteristics of patients

Data were obtained from 1488 patients. Among them, only $190(12.8 \%)$ had been diagnosed with early-stage NPC, and related information was successfully collected from 118 of these patients. Of the 118 earlystage patients, 80 were each matched with two patients with late-stage disease, and 38 were each matched with three patients with late-stage disease; therefore, a total of 274 late-stage patients were recruited. Overall, $66.3 \%$ of patients were male (77 with early-stage disease and 183 with late-stage disease), and $33.7 \%$ were female (41 with early-stage disease and 91 with late-stage disease). Furthermore, $71.4 \%$ of patients (83 with early-stage disease and 197 with late-stage disease) resided in urban regions, and $28.6 \%$ (35 with early-stage disease and 77 with late-stage disease) in rural regions. The median age was 43 years for both early-stage and late-stage patients, with ranges of 16-68 years and 14-72 years, respectively. Because of the matched design, no differences were observed between the two groups.

\section{MCA of SES indicators}

Figure 1 displays the results for the first two dimensions (axes) of the MCA, which included all patients with early-stage and late-stage diseases. Because the first dimension covered most (76.7\%) of the total Chi square variations in the data, it was used for further analyses. In this figure, the indicators associated with higher wealth are presented at the bottom half of the plot, whereas the indicators of lower wealth are located on the upper half.

\section{Association between SES and NPC stage at diagnosis}

The ORs (95\% CIs) for the associations of SES indicators with clinical stage of NPC at diagnosis are displayed in Table 1. Compared with patients who had a middle school or lower education level, patients with a high school or higher education level was not associated with a decreased risk of late diagnosis (adjusted OR 0.58; 95\% CI 0.32-1.05). Before model adjustment, skilled workers were more likely than unskilled workers to receive an early diagnosis (crude OR 0.52; 95\% CI 0.28-0.98), but this association disappeared after model adjustment (adjusted OR 0.57; 95\% CI 0.27-1.22). Neither health insurance nor working hours per week was associated with the risk of late diagnosis. Those lived with 2-3 family members were more likely to receive an early diagnosis than those lived with $0-1$ family members (adjusted OR 0.48; 95\% CI 0.23-0.98). After model adjustment, 


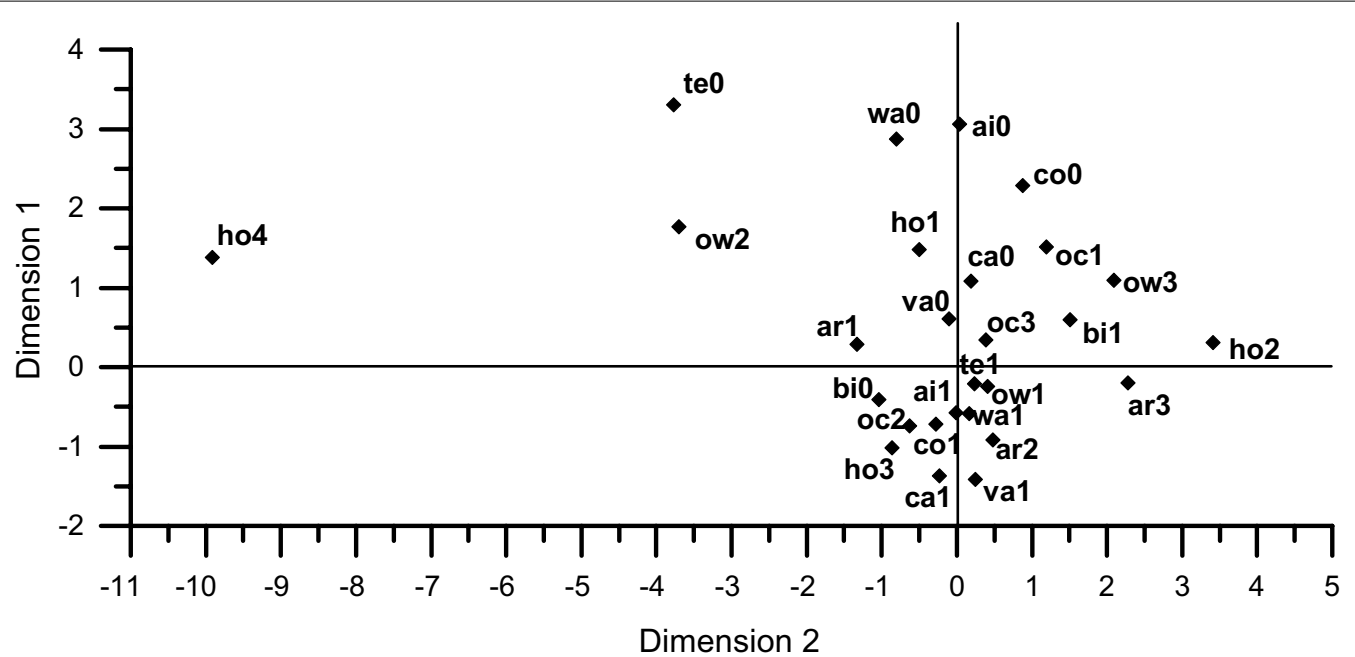

Fig. 1 Visualization of the coordinates of wealth variables included in the multiple correspondence analysis (MCA) of 118 early-stage nasopharyngeal carcinoma (NPC) patients and 274 late-stage NPC patients. Appliance ownership: bi motorbike, co computer, va vacuum cleaner, wa washing machine, $c a$ automobile, ai air conditioner, te television. The suffix " 0 " indicates non-ownership of the appliance; the suffix "1" indicates ownership. Housing: ow 1 owned a residence, ow2 rented a residence, ow 3 other types of ownership, ho 1 bungalow, ho2 house, ho3 apartment, ho4 other types of residence structure, ar 1 first tertile of residence area, ar2 second tertile of residence area, ar 3 third tertile of residence area. Occupation: oc1 unskilled workers, oc2 skilled worker, oc3 retired or unemployed. The indicators associated with higher wealth gather along the bottom half of the plot, whereas the indicators of lower wealth are located on the upper half. Dimensions 1 and 2 cover $76.7 \%$ and $10.2 \%$ of the total Chi square variations in the data

no associations of residence ownership, residence structure, residence size, and residence size per person were observed with the risk of late diagnosis. Interestingly, owning a motorbike (OR 0.38; 95\% CI 0.23-0.64) was associated with an early diagnosis after adjusting for education level, smoking history, salted fish consumption, and family cancer history, except for the wealth score. This association remained after the wealth score was added to the adjusted factors (OR 0.29; 95\% CI 0.160.41). No associations were observed for the ownership of other appliances.

For the results of composite wealth score, we have to note that the wealthiest patients had negative scores because expensive appliances were located on the bottom half of the MCA plot. Compared with a composite wealth score lower than -3.9 , a composite wealth score higher than 1.1 showed no significant association with late diagnosis of NPC in either the univariate or the multivariate models, although the point estimate was quite bigger than one.

\section{Association between NPC risk factors and NPC stage at diagnosis}

As shown in Table 1, a family cancer history was not found to associate with the risk of late diagnosis. Surprisingly, smoking cessation, compared with no smoking history, was associated with early diagnosis (adjusted OR
$0.29 ; 95 \%$ CI 0.11-0.77). Smoking more than 30 (adjusted OR 11.46; 95\% CI 1.26-103.91) or 10-30 cigarettes per day (adjusted OR 4.03; 95\% CI 1.11-14.68) was significantly associated with the risk of a late diagnosis when compared with smoking fewer than ten cigarettes per day ( $P$ for trend $=0.015$ ). Compared with seldom or never eating salted fish, eating salted fish every week was associated with an increased risk of late diagnosis in the univariate analysis (crude OR 1.89; 95\% CI 1.07-3.34), but not in the multivariate analyses (adjusted OR 1.71; $95 \%$ CI 0.93-3.17).

\section{Associations between physical examination, patient interval, NPC-related knowledge, and NPC stage at diagnosis}

As shown in Table 1, knowing about NPC early symptoms was associated with an increased likelihood of early diagnosis as compared with not having the knowledge (adjusted OR 0.60; 95\% CI 0.37-0.98). In contrast, no association was observed between knowledge about risk factors and an early diagnosis. Taking physical examination increased the likelihood of an early diagnosis (adjusted OR 0.50; 95\% CI 0.28-0.89). In addition, a patient interval of 3 or more months was associated with an increased risk of late diagnosis (adjusted OR 1.83; 95\% CI 1.07-3.13), compared with a shorter interval. 
Table 1 Associations of potential factors with NPC stage at diagnosis

\begin{tabular}{|c|c|c|c|c|}
\hline \multirow[t]{2}{*}{ Variable } & \multicolumn{2}{|c|}{ NPC stage at diagnosis [cases (\%)] } & \multirow[t]{2}{*}{ Crude OR $(95 \% \mathrm{Cl})$} & \multirow[t]{2}{*}{ Adjusted OR $(95 \% \mathrm{Cl})^{2}$} \\
\hline & Early stage & Late stage & & \\
\hline \multicolumn{5}{|l|}{ Education level } \\
\hline Middle school or lower & $45(38.1)$ & $132(48.2)$ & 1.00 & 1.00 \\
\hline High school or higher & $73(61.9)$ & $142(51.8)$ & $0.56(0.33-0.95)^{*}$ & $0.58(0.32-1.05)$ \\
\hline \multicolumn{5}{|l|}{ Occupation } \\
\hline Unskilled workers & $22(18.6)$ & $67(24.5)$ & 1.00 & 1.00 \\
\hline Skilled workers & $75(63.6)$ & $144(52.5)$ & $0.52(0.28-0.98)^{*}$ & $0.57(0.27-1.22)$ \\
\hline Retired or unemployed & $21(17.8)$ & $63(23.0)$ & $0.95(0.44-2.06)$ & $0.99(0.42-2.32)$ \\
\hline \multicolumn{5}{|l|}{ Working hours per week ${ }^{b}$} \\
\hline $0-30$ & $33(28.2)$ & $87(31.8)$ & 1.00 & 1.00 \\
\hline $31-50$ & $48(41.0)$ & $91(33.2)$ & $0.70(0.38-1.28)$ & $0.75(0.38-1.48)$ \\
\hline 51 or more & $36(30.8)$ & $96(35.0)$ & $0.95(0.50-1.78)$ & $0.81(0.40-1.63)$ \\
\hline \multicolumn{5}{|l|}{ Insurance } \\
\hline UBMI1 & $72(61.0)$ & $168(61.3)$ & 1.00 & 1.00 \\
\hline NRCMS & $37(31.4)$ & $86(31.4)$ & $1.13(0.58-2.22)$ & $1.14(0.50-2.60)$ \\
\hline UBMI2 & $6(5.1)$ & $4(1.5)$ & $0.25(0.07-0.91)^{*}$ & $0.31(0.08-1.23)$ \\
\hline Others & $3(2.5)$ & $16(5.8)$ & $2.60(0.72-9.41)$ & $2.10(0.51-8.62)$ \\
\hline \multicolumn{5}{|l|}{ Number of family members ${ }^{c}$} \\
\hline First tertile (1-2) & $12(10.3)$ & $52(19.0)$ & 1.00 & 1.00 \\
\hline Second tertile (3-4) & $75(64.7)$ & $129(47.1)$ & $0.41(0.21-0.82)^{*}$ & $0.48(0.23-0.98)^{*}$ \\
\hline Third tertile $(\geq 5)$ & $29(25.0)$ & $93(33.9)$ & $0.73(0.34-1.55)$ & $0.83(0.37-1.86)$ \\
\hline \multicolumn{5}{|l|}{ Residence ownership ${ }^{d}$} \\
\hline No & $18(15.4)$ & $31(11.3)$ & 1.00 & 1.00 \\
\hline Yes & 99 (84.6) & $243(88.7)$ & $1.35(0.73-2.49)$ & $1.77(0.81-3.88)$ \\
\hline \multicolumn{5}{|l|}{ Residence structure } \\
\hline Bungalow & $31(26.3)$ & $88(32.1)$ & 1.00 & 1.00 \\
\hline House & $22(18.6)$ & $51(18.6)$ & $0.82(0.43-1.55)$ & $1.04(0.51-2.12)$ \\
\hline Apartment & $64(54.2)$ & $133(48.6)$ & $0.68(0.40-1.17)$ & $0.99(0.50-1.96)$ \\
\hline Others & $1(0.8)$ & $2(0.7)$ & $0.69(0.06-8.04)$ & $0.68(0.06-8.17)$ \\
\hline \multicolumn{5}{|l|}{ Residence size $\left(\mathrm{m}^{2}\right)$} \\
\hline First tertile $(<100)$ & $66(56.0)$ & $160(58.4)$ & 1.00 & 1.00 \\
\hline Second tertile (100-120) & $19(16.0)$ & $24(8.8)$ & $0.52(0.27-1.02)$ & $0.61(0.29-1.29)$ \\
\hline Third tertile (>120) & $33(28.0)$ & $90(32.8)$ & $1.15(0.70-1.90)$ & $1.13(0.65-1.96)$ \\
\hline \multicolumn{5}{|l|}{ Area per person $\left(\mathrm{m}^{2}\right)^{\mathrm{e}}$} \\
\hline First tertile $(<24)$ & $27(23.3)$ & $82(30.0)$ & 1.00 & 1.00 \\
\hline Second tertile (24-35) & $50(43.1)$ & $96(35.0)$ & $0.60(0.33-1.07)$ & $0.64(0.33-1.24)$ \\
\hline Third tertile (>35) & 39 (33.6) & $96(35.0)$ & $0.76(0.42-1.38)$ & $0.80(0.41-1.55)$ \\
\hline \multicolumn{5}{|l|}{ Appliance ownership ${ }^{f}$} \\
\hline Car & $56(48.7)$ & $116(42.3)$ & $0.74(0.46-1.20)$ & $0.78(0.47-1.29)$ \\
\hline Motorbike & $63(54.3)$ & $97(35.4)$ & $0.45(0.29-0.71)^{*}$ & $0.38(0.23-0.64)^{*}$ \\
\hline Computer & $89(76.7)$ & $207(75.5)$ & $0.84(0.46-1.53)$ & $0.86(0.45-1.63)$ \\
\hline Television & $111(95.7)$ & $256(93.4)$ & $0.58(0.20-1.66)$ & $0.66(0.22-2.03)$ \\
\hline Air conditioner & $102(87.9)$ & $226(82.5)$ & $0.48(0.22-1.05)$ & $0.52(0.23-1.19)$ \\
\hline Washing machine & 97 (83.6) & $227(82.8)$ & $0.86(0.44-1.66)$ & $0.93(0.46-1.87)$ \\
\hline Vacuum cleaner & $38(32.8)$ & $80(29.2)$ & $0.86(0.54-1.36)$ & $0.89(0.54-1.45)$ \\
\hline \multicolumn{5}{|l|}{ Wealth score ${ }^{g}$} \\
\hline First tertile $(<-3.9)$ & $44(37.3)$ & $83(30.3)$ & 1.00 & 1.00 \\
\hline Second tertile ( -3.9 to 1.1$)$ & $38(32.2)$ & 93 (33.9) & $1.29(0.76-2.19)$ & $1.26(0.72-2.20)$ \\
\hline Third tertile $(>1.1)$ & $36(30.5)$ & $98(35.8)$ & $1.64(0.90-2.99)$ & $1.75(0.88-3.47)$ \\
\hline
\end{tabular}


Table 1 continued

\begin{tabular}{|c|c|c|c|c|}
\hline \multirow[t]{2}{*}{ Variable } & \multicolumn{2}{|c|}{ NPC stage at diagnosis [cases (\%)] } & \multirow[t]{2}{*}{ Crude OR $(95 \% \mathrm{Cl})$} & \multirow[t]{2}{*}{ Adjusted OR $(95 \% \mathrm{Cl})^{\mathrm{a}}$} \\
\hline & Early stage & Late stage & & \\
\hline \multicolumn{5}{|c|}{ Family cancer history } \\
\hline None & $78(66.1)$ & $189(69.0)$ & 1.00 & 1.00 \\
\hline NPC & $18(15.3)$ & $36(13.1)$ & $0.86(0.46-1.61)$ & $0.78(0.40-1.53)$ \\
\hline Other cancers & $22(18.6)$ & 49 (17.9) & $0.95(0.54-1.67)$ & $0.93(0.51-1.72)$ \\
\hline \multicolumn{5}{|l|}{ Smoking history } \\
\hline Never smoker & $74(62.7)$ & $160(58.4)$ & 1.00 & 1.00 \\
\hline Former smoker & $18(15.3)$ & $14(5.1)$ & $0.35(0.14-0.85)^{*}$ & $0.29(0.11-0.77)^{*}$ \\
\hline Current smoker & $26(22.0)$ & $100(36.5)$ & $1.72(0.93-3.19)$ & $1.75(0.92-3.32)$ \\
\hline \multicolumn{5}{|c|}{ Cigarette number per day ${ }^{h}$} \\
\hline$<10$ & $22(51.2)$ & $31(27.2)$ & 1.00 & 1.00 \\
\hline $10-30$ & $19(44.2)$ & $66(57.9)$ & $2.87(1.14-7.25)^{*}$ & $4.03(1.11-14.68)^{*}$ \\
\hline$>30$ & $2(4.6)$ & $17(14.9)$ & $6.04(1.09-33.32)^{*}$ & $11.46(1.26-103.91)^{*}$ \\
\hline \multicolumn{5}{|c|}{ Salted fish consumption ${ }^{i}$} \\
\hline Seldom or never & $72(61.5)$ & $131(48.0)$ & 1.00 & 1.00 \\
\hline Every month & $25(21.4)$ & $70(25.6)$ & $1.58(0.91-2.74)$ & $1.53(0.85-2.73)$ \\
\hline Every week & $20(17.1)$ & $72(26.4)$ & $1.89(1.07-3.34)^{*}$ & $1.71(0.93-3.17)$ \\
\hline \multicolumn{5}{|c|}{ Knowledge of NPC early symptoms } \\
\hline No & $40(33.9)$ & $138(50.4)$ & 1.00 & 1.00 \\
\hline Yes & $78(66.1)$ & $136(49.6)$ & $0.54(0.35-0.83)^{*}$ & $0.60(0.37-0.98)^{*}$ \\
\hline \multicolumn{5}{|c|}{ Knowledge of NPC risk factors } \\
\hline No & $88(74.6)$ & $223(81.4)$ & 1.00 & 1.00 \\
\hline Yes & $30(25.4)$ & $51(18.6)$ & $0.66(0.38-1.12)$ & $0.74(0.42-1.31)$ \\
\hline \multicolumn{5}{|l|}{ Physical examination } \\
\hline Never & $51(43.2)$ & $167(60.9)$ & 1.00 & 1.00 \\
\hline Ever & $67(56.8)$ & $107(39.1)$ & $0.40(0.24-0.67)^{*}$ & $0.50(0.28-0.89)^{*}$ \\
\hline \multicolumn{5}{|c|}{ Patient interval (months) } \\
\hline$\leq 3$ & $95(80.5)$ & $188(68.6)$ & 1.00 & 1.00 \\
\hline$>3$ & $23(19.5)$ & $86(31.4)$ & $1.87(1.13-3.11)^{*}$ & $1.83(1.07-3.13)^{*}$ \\
\hline
\end{tabular}

OR odds ratio, $C /$ confidence interval, UBMI1 urban basic medical insurance uncovering state-owned enterprise employees and government staffs, NRCMS new rural cooperative medical scheme, UBMI2 urban basic medical insurance of state-owned enterprise employees and government staffs

* Statistically significant results

a Adjusted for education level, wealth score, smoking history, salted fish consumption, and family cancer history. When one of these possible confounders was the variable of interest, the other possible confounders were adjusted

${ }^{b}$ Data was missing for one patient in the early stage group

c Data was missing for two patients in the early stage group

d Data was missing for one patient in the early stage group

e Data was missing for two patients in the early stage group

${ }^{f}$ For each appliance, the reference group comprised the subjects that did not own the appliance. The multivariate analysis of these appliance ownership variables was not adjusted for the wealth score

$g$ Because appliances associated with higher wealth are located on the bottom half of the multiple correspondence analysis (MCA) graph, a lower score indicates a higher level of wealth

h We only included former and current smokers. The multivariate analysis of the number of cigarettes per day was not adjusted for the smoking history

i Data was missing for one patient in the early stage group and one in the late stage group

\section{Discussion}

The present study identified associations of several SES indicators, including the number of family members living together and whether owning a motorbike, with the clinical stage of NPC at diagnosis. However, the composite wealth score and other SES indicators were not found to associate with the risk of late diagnosis. In addition, knowledge about early symptoms of NPC, the patient interval, physical examination, and smoking history and frequency were found to associate with the clinical stage of NPC at diagnosis.

It can be difficult to collect income-related information during epidemiological studies, and wealth can 
differ dramatically across different social groups even if incomes are similar [29]. Investigations of nonmonetary indicators of wealth, such as appliance ownership, housing conditions, and occupation, have been shown to be less sensitive and relatively accurate $[26,30]$. We therefore collected information about the patients' occupations, residence ownership, size, and structure, and household appliance ownership to measure their wealth. Interestingly, although owning a car or vacuum cleaner was associated with the highest level of wealth in the MCA, they were not related to an early diagnosis of NPC. In contrast, owning a motorbike was associated with an early diagnosis after adjusting for the wealth score, suggesting that this factor might substitute for other factors in the exclusion of wealth. In the present study, patients in rural areas were statistically more likely to own a motorbike than those in urban areas (data not shown). In addition, as many Chinese cities have banned motorbikes in downtown areas [31], most urban motorbike owners live in suburbs. Motorbikes provide patients in rural and suburban areas with a rapid, convenient transportation to healthcare facilities, which tend to be located in relatively distant areas [14]. We speculated that owning a car, an indicator of wealth, was a characteristic of subjects who lived in downtown areas with adjacent healthcare facilities that were also easy to reach by public transportation [14]. Therefore, car ownership might not provide the same significant benefit as motorbike ownership.

The association between a high education level and early NPC diagnosis was not significant in our study. In contrast, the association between knowledge about early NPC symptoms and early diagnosis was significant. Therefore, it is reasonable to assume that knowledge about early symptoms had a stronger effect on the likelihood of an early diagnosis of NPC than the general education level. Accordingly, we recommend that governmental and healthcare facilities educate the public about early NPC symptoms to effectively increase the early diagnosis rate.

We surveyed several factors associated with living conditions and household density, including the total residence size, number of family members living together, and residence size per person, as potential indicators of SES. A shared residence with 3-4 family members, compared with 1-2 family members, was more strongly associated with an early diagnosis of NPC, which could be attributed to the increased support and intimate relationships among family members [32]. For example, close family relationships might lead to the disclosure of a symptom to a family member and could potentially reduce the delay in presenting the symptom to a general practitioner [33]. However, people living in crowded accommodations might also be prone to insufficient diets and infectious disease [34, 35], which could explain why living with 5 or more family members was not related to the likelihood of an early diagnosis.

We used a composite wealth score, calculated by adding the MCA scores for ownership of different appliances, occupation, and residence structure, size, and ownership, to measure each patient's overall wealth status. This measurement of wealth was proved to be accurate in another study conducted in an under-developed country [26]. In the present study, we did not find an association of the composite wealth score or any other wealth indicators with the clinical stage at diagnosis, leading us to postulate that wealth is not associated with the clinical stage of NPC at diagnosis. The composite wealth score was further used as an integrated variable to control the potential confounding bias induced by the components of the score.

A patient interval of 3 months or longer was associated with a late diagnosis of NPC, which agreed with the findings of similar studies in which physical examination and knowledge about early symptoms played important roles in reducing the patient interval and promoting diagnosis at an early stage $[36,37]$. In the present study, physical examination was also associated with early NPC diagnosis. The examinations tend to include cancer screening tests and are considered useful for reducing the patient interval and detecting cancer at early stages [22, 38]. For NPC, EBV serology test was found to be a useful NPC screening tool in a high-risk population [39, 40]. Similarly, knowledge about early symptoms of NPC was associated with early diagnosis, consistent with previous studies that described the recognition and perception of symptoms as the first and most important step toward seeking medical help and reducing the patient interval [41-44]. On the other hand, no significant association was found between knowledge about NPC risk factors and early diagnosis of NPC, in contrast to the findings of a study on oral and pharyngeal carcinoma [44]. However, known NPC risk factors, such as cigarette smoking history and frequency, were associated with late diagnosis of NPC in the present study, suggesting that knowledge about risk factors did not lead to positive health behaviors. Therefore, to reduce the patient interval and increase the rate of early diagnosis, promoting physical examinations and education about early symptoms of NPC could be more effective than promoting education about NPC risk factors.

In the present study, smoking cessation was associated with early NPC diagnosis when compared with never smoked. We assumed that people who had quit smoking may have been more conscious of health issues. In previous studies, most smokers expressed regret that they had begun smoking and worried about the future 
effects of smoking on their health and quality of life [45, 46]. Furthermore, smokers who had quit or intended to quit smoking were likely to have more access to beneficial health information [47]. However, the pernicious effects of smoking are undisputed. We found that daily smoking amount was strongly associated with late diagnosis of NPC in a dose-response manner indicated by the observed significant trends. We further assumed that smoking is a significant tumor growth promoting factor, because cigarette smoke has mutagenic and DNA-damaging effects that lead to the malignant transformation of normal epithelial cells in the nasopharynx [48, 49]. Immunologically, cigarette smoking may suppress natural killer cell activation and cytotoxicity, which could further alter the tumor microenvironment, promote tumor progression and metastasis, and increase the tumor burden $[50,51]$.

In the present study, we used a case-control design to establish a new, efficient approach so as to identify potential factors associated with the clinical stage of NPC at diagnosis. In case-control studies, the cases are usually patients who have experienced relatively rare events. In the present study, only 190 of 1488 NPC patients were diagnosed at an early stage. Therefore, we defined earlystage NPC patients as cases and matched them with latestage NPC patients by sex, age, and residency. This design allowed us to find subtler differences between late-stage and early-stage NPC patients. If we had designated latestage NPC patients as cases, we might not have had an adequate number of matched early-stage NPC patients. We note that as few patients are diagnosed at early stages in other cancers, this approach could be implemented in similar studies.

The present study probed potential factors associated with the clinical stage of NPC at diagnosis by investigating a comprehensive number of possible factors with individual-level indicators. Unlike similar studies of other cancers that used neighborhood-level indicators [14-16], individual-level indicators are more accurate and less prone to ecological bias and misclassification. Moreover, the use of the composite wealth score rather than a single indicator allowed us to more accurately measure patients' wealth statuses [26]. To eliminate confounding effect between indicators, we adjusted for several important potential confounders, such as NPC risk factors, the composite wealth score, and education. Although many factors were statistically insignificant, the indicators with null associations would at least have weaker effects on clinical NPC stage at diagnosis than the indicators that were significant.

Because the interactions among viral infections, genetic factors, and environment are not fully understood, secondary NPC prevention tends to be more cost-effective than primary prevention [2]. Measures aimed at improving the early NPC diagnosis rate will likely increase survival rates and ease the medical burdens on patients and healthcare systems. Our findings suggest that high-risk populations should be targeted to improve health awareness by providing education related to early NPC symptoms and encouraging routine physical examinations. Furthermore, governments should provide more convenient access to healthcare facilities, and smokers should reduce and quit smoking as soon as possible. Contrary to other studies, we found that measures such as improving the general education level and SES might not be as effective as the measures mentioned above. However, the present study only provides a general orientation, and we hope future studies will offer more detailed measures.

One limitation of this study was the collection of information about previous exposures. Nevertheless, we reduced the likelihood of recall bias by surveying facts that could be recalled truthfully, such as the level of education or occupation. Another limitation was the relatively small number of study subjects and inclusion of patients from a single hospital. Accordingly, we could not exclude an occasional association. A multicenter study with a large sample is needed to confirm our results.

\section{Conclusions}

In summary, the present study suggested that factors related to cigarette smoking, easy access to healthcare facilities, health awareness, knowledge of early NPC symptoms, and early NPC detection were strongly associated with the clinical stage of NPC at diagnosis. In contrast, the wealth score and other SES indicators had limited effects. Therefore, to increase the rate of early diagnosis and improve the prognosis of NPC patients, high-risk populations should be targeted by initiatives aimed at improving health awareness and reducing patient interval through education on early NPC symptoms, promoting routine physical examination, and improving the accessibility to healthcare facilities. Furthermore, smokers must reduce their cigarette consumption and ultimately quit smoking. However, multicenter large-sample studies are needed to confirm our results. Finally, the case-control design of the present study provided a new, efficient approach to the investigation of factors related to the clinical stage of NPC at diagnosis.

\section{Abbreviations}

NPC: nasopharyngeal carcinoma; SES: socioeconomic status; MCA: multiple correspondence analysis; AJCC/UICC: American Joint Committee on Cancer/ Union for International Cancer Control; UBMI1: urban basic medical insurance excluding state-owned enterprise employees and government staffs; NRCMS: new rural cooperative medical scheme; UBMI2: urban basic medical insurance of state-owned enterprise employees and government staffs. 


\section{Authors' contributions}

JTR and MYL contributed equally to the study design, data acquisition, analysis and interpretation, and manuscript drafting. WXW, WQX, ZFR, and WHJ contributed to the study concept and design, data interpretation, and critical manuscript revision. All authors read and approved the final manuscript.

\section{Acknowledgements}

This work was supported by the National Science Fund for Distinguished Young Scholars of China (No. 81325018) and the Key Project for International Cooperation and Exchange of the National Natural Science Foundation of China (No. 81220108022).

\section{Competing interests}

The authors declare that they have no competing interests.

\section{Availability of data and materials}

This manuscript does not describe a new application/tool or software to share. Raw data are available for sharing if needed.

Received: 29 September 2016 Accepted: 04 July 2017

Published online: 04 September 2017

\section{References}

1. Torre LA, Bray F, Siegel RL, Ferlay J, Lortet-Tieulent J, Jemal A. Global cancer statistics, 2012. CA Cancer J Clin. 2015;65(2):87-108.

2. Cao SM, Simons MJ, Qian CN. The prevalence and prevention of nasopharyngeal carcinoma in China. Chin J Cancer. 2011;30(2):114-9.

3. Ghandri N, Gabbouj S, Farhat K, Bouaouina N, Abdelaziz H, Nouri A, et al. Association of HLA-G polymorphisms with nasopharyngeal carcinoma risk and clinical outcome. Hum Immunol. 2011;72(2):150-8.

4. Guo R, Chen XZ, Chen L, Jiang F, Tang LL, Mao YP, et al. Comorbidity predicts poor prognosis in nasopharyngeal carcinoma: development and validation of a predictive score model. Radiother Oncol. 2015;114(2):249-56.

5. Teppo L, Dickman PW, Hakulinen T, Luostarinen T, Pukkala E, Sankila $\mathrm{R}$, et al. Cancer patient survival — patterns, comparisons, trendsa population-based Cancer Registry study in Finland. Acta Oncol. 1999;38(3):283-94.

6. Xiao WW, Han F, Lu TX, Chen CY, Huang Y, Zhao C. Treatment outcomes after radiotherapy alone for patients with early-stage nasopharyngeal carcinoma. Int J Radiat Oncol Biol Phys. 2009;74(4):1070-6.

7. Wang HY, Chang YL, To KF, Hwang JS, Mai HQ, Feng YF, et al. A new prognostic histopathologic classification of nasopharyngeal carcinoma. Chin J Cancer. 2016;35:41.

8. Huang PY, Zeng Q, Cao KJ, Guo X, Guo L, Mo HY, et al. Ten-year outcomes of a randomised trial for locoregionally advanced nasopharyngeal carcinoma: a single-institution experience from an endemic area. Eur J Cancer. 2015;51(13):1760-70.

9. Weller D, Vedsted P, Rubin G, Walter FM, Emery J, Scott S, et al. The Aarhus statement: improving design and reporting of studies on early cancer diagnosis. Br J Cancer. 2012;106(7):1262-7.

10. Al-Rajhi N, El-Sebaie M, Khafaga Y, AlZahrani A, Mohamed G, Al-Amro A. Nasopharyngeal carcinoma in Saudi Arabia: clinical presentation and diagnostic delay. East Mediterr Health J. 2009;15(5):1301-7.

11. Sheng $L$, Shui Y, Shen L, Wei Q. Effect of patient-related delay in diagnosis on the extent of disease and prognosis in nasopharyngeal carcinoma. Am J Rhinol. 2008;22(3):317-20.

12. Leong $J$, Fong KW, Low WK. Factors contributing to delayed diagnosis in nasopharyngeal carcinoma. J Laryngol Otol. 1999;113(7):633-6.

13. Olsen MH, Boje CR, Kjaer TK, Steding-Jessen M, Johansen C, Overgaard J, et al. Socioeconomic position and stage at diagnosis of head and neck cancer - a nationwide study from DAHANCA. Acta Oncol. 2015;54(5):759-66.

14. Lin Y, Wimberly MC. Geographic variations of colorectal and breast cancer late-stage diagnosis and the effects of neighborhood-level factors. J Rural Health. 2017;33(2):146-57.

15. Tervonen HE, Walton R, Roder D, You H, Morrell S, Baker D, et al. Sociodemographic disadvantage and distant summary stage of cancer at diagnosis - a population-based study in New South Wales. Cancer Epidemiol. 2016;40:87-94.

16. Seneviratne S, Lawrenson R, Harvey V, Ramsaroop R, Elwood M, Scott $\mathrm{N}$, et al. Stage of breast cancer at diagnosis in New Zealand: impacts of socio-demographic factors, breast cancer screening and biology. BMC Cancer. 2016;16:129.

17. Galobardes B, Shaw M, Lawlor DA, Lynch JW, Davey Smith G. Indicators of socioeconomic position (part 2). J Epidemiol Community Health. 2006;60(2):95-101.

18. Diderichsen F, Andersen I, Manuel C, Andersen AM, Bach E, Baadsgaard $M$, et al. Health inequality - determinants and policies. Foreword. Scand J Public Health. 2012;40(8 Suppl):10-1.

19. Chang TS, Chang CM, Hsu TW, Lin YS, Lai NS, Su YC, et al. The combined effect of individual and neighborhood socioeconomic status on nasopharyngeal cancer survival. PLOS ONE. 2013;8(9):e73889.

20. McCutchan GM, Wood F, Edwards A, Richards R, Brain KE. Influences of cancer symptom knowledge, beliefs and barriers on cancer symptom presentation in relation to socioeconomic deprivation: a systematic review. BMC Cancer. 2015;15:1000.

21. Huang C, Liu CJ, Pan XF, Liu X, Li NX. Correlates of unequal access to preventive care in China: a multilevel analysis of national data from the 2011 China Health and Nutrition Survey. BMC Health Serv Res. 2016:16(1):177.

22. Jung HM, Lee JS, Lairson DR, Kim Y. The effect of national cancer screening on disparity reduction in cancer stage at diagnosis by income level. PLOS ONE. 2015;10(8):e0136036.

23. Wang N, Cao F, Liu F, Jia Y, Wang J, Bao C, et al. The effect of socioeconomic status on health-care delay and treatment of esophageal cancer. J Transl Med. 2015;13:241.

24. Jia WH, Qin HD. Non-viral environmental risk factors for nasopharyngeal carcinoma: a systematic review. Semin Cancer Biol. 2012;22(2):117-26.

25. Poh SS, Chua ML, Wee JT. Carcinogenesis of nasopharyngeal carcinoma: an alternate hypothetical mechanism. Chin J Cancer. 2016;35:9.

26. Islami F, Kamangar F, Nasrollahzadeh D, Aghcheli K, Sotoudeh M, AbediArdekani B, et al. Socio-economic status and oesophageal cancer: results from a population-based case-control study in a high-risk area. Int J Epidemiol. 2009;38(4):978-88.

27. Dohoo IR, Ducrot C, Fourichon C, Donald A, Hurnik D. An overview of techniques for dealing with large numbers of independent variables in epidemiologic studies. Prev Vet Med. 1997;29(3):221-39.

28. Akassou A, Yacoubi H, Jamil A, Dakka N, Amzazi S, Sadki K, et al. Prevalence of HLA-B27 in Moroccan healthy subjects and patients with ankylosing spondylitis and mapping construction of several factors influencing AS diagnosis by using multiple correspondence analysis. Rheumatol Int. 2015:35(11):1889-94.

29. Berkman LF, Macintyre S. The measurement of social class in health studies: old measures and new formulations. IARC Sci Publ. 1997;138:51-64.

30. Pollack CE, Chideya S, Cubbin C, Williams B, Dekker M, Braveman P. Should health studies measure wealth? A systematic review. Am J Prev Med. 2007;33(3):250-64.

31. Xu J. Drive-away policing and situational crime prevention in China: an analysis of motorcycle ban (jinmo) policy in Guangzhou. Int J Offender Ther Comp Criminol. 2012;56(2):239-64.

32. Liang J, Gu S, Krause N. Social support among the aged in Wuhan, China. Asia Pac Popul J. 1992;7(3):33-62.

33. Burgess CC, Ramirez AJ, Richards MA, Love SB. Who and what influences delayed presentation in breast cancer? Br J Cancer. 1998;77(8):1343-8.

34. Lundberg $O$. The impact of childhood living conditions on illness and mortality in adulthood. Soc Sci Med. 1993;36(8):1047-52.

35. Hart CL, Smith GD. Relation between number of siblings and adult mortality and stroke risk: 25 year follow up of men in the collaborative study. J Epidemiol Community Health. 2003;57(5):385-91.

36. Ozturk C, Fleer J, Hoekstra HJ, Hoekstra-Weebers JE. Delay in diagnosis of testicular cancer; a need for awareness programs. PLOS ONE. 2015;10(11):e0141244.

37. Unger-Saldana K, Miranda A, Zarco-Espinosa G, Mainero-Ratchelous F, Bargallo-Rocha E, Miguel Lazaro-Leon J. Health system delay and its effect on clinical stage of breast cancer: multicenter study. Cancer. 2015;121(13):2198-206.

38. Shridhar K, Dey S, Bhan CM, Bumb D, Govil J, Dhillon PK. Cancer detection rates in a population-based, opportunistic screening model, New Delhi, India. Asian Pac J Cancer Prev. 2015;16(5):1953-8. 
39. Ng WT, Yau TK, Yung RW, Sze WM, Tsang AH, Law AL, et al. Screening for family members of patients with nasopharyngeal carcinoma. Int J Cancer. 2005;113(6):998-1001.

40. Feng FT, Cui Q, Liu WS, Guo YM, Feng QS, Chen LZ, et al. A single nucleotide polymorphism in the Epstein-Barr virus genome is strongly associated with a high risk of nasopharyngeal carcinoma. Chin J Cancer 2015;34(12):563-72.

41. Khakbazan Z, Roudsari RL, Taghipour A, Mohammadi E, Pour RO. Appraisal of breast cancer symptoms by Iranian women: entangled cognitive, emotional and socio-cultural responses. Asian Pac J Cancer Prev. 2014;15(19):8135-42.

42. Lam WW, Tsuchiya M, Chan M, Chan SW, Or A, Fielding R. Help-seeking patterns in Chinese women with symptoms of breast disease: a qualitative study. J Public Health. 2009;31(1):59-68.

43. O'Mahony M, Hegarty J. Help seeking for cancer symptoms: a review of the literature. Oncol Nurs Forum. 2009;36(4):E178-84.

44. Park JH, Slack-Smith L, Smith A, Frydrych AM, O'Ferrall I, Bulsara M. Knowledge and perceptions regarding oral and pharyngeal carcinoma among adult dental patients. Aust Dent J. 2011;56(3):284-9.

45. Fong GT, Hammond D, Laux FL, Zanna MP, Cummings KM, Borland R, et al. The near-universal experience of regret among smokers in four countries: findings from the International Tobacco Control Policy Evaluation Survey. Nicotine Tob Res. 2004;6(Suppl 3):S341-51.
46. Schnoll RA, Malstrom M, James C, Rothman RL, Miller SM, Ridge JA, et al. Processes of change related to smoking behavior among cancer patients. Cancer Pract. 2002;10(1):11-9.

47. Jung M. Exploring socio-contextual factors associated with male smoker's intention to quit smoking. BMC Public Health. 2016;16:398.

48. Furmanski P. Revealing the mechanism of tissue damage due to tobacco use: finally, a smoking gun? Am J Pathol. 2013;182(5):1489-93.

49. Ji X, Zhang W, Xie C, Wang B, Zhang G, Zhou F. Nasopharyngeal carcinoma risk by histologic type in central China: impact of smoking, alcohol and family history. Int J Cancer. 2011;129(3):724-32

50. Stojanovic A, Cerwenka A. Natural killer cells and solid tumors. J Innate Immun. 2011;3(4):355-64.

51. Lu LM, Zavitz CC, Chen B, Kianpour S, Wan Y, Stampfli MR. Cigarette smoke impairs NK cell-dependent tumor immune surveillance. J Immunol. 2007;178(2):936-43.

\section{Submit your next manuscript to BioMed Central and we will help you at every step:}

- We accept pre-submission inquiries

- Our selector tool helps you to find the most relevant journal

- We provide round the clock customer support

- Convenient online submission

- Thorough peer review

- Inclusion in PubMed and all major indexing services

- Maximum visibility for your research

Submit your manuscript at www.biomedcentral com/submit 